\title{
THE EFFECT OF PANCURONIUM ON REFLEX REGULATION OF HEART RATE IN MAN*
}

\author{
P.C. Duke, M.D., F.R.C.P.(C), G. MitTleR, B.SC., \\ AND J.G. WADE, M.P., F.R.C.P.(c)
}

Pancuronium bromide (NA-97, Pavulon-Organon) is a new non-deplorizing competitive neuromuscular blocking agent. Its clinical blocking properties are similar to d-tubocurarine and are associated with hypotension, ganglionic blockade, and histamine release. ${ }^{3.5-14}$ Despite some variation most studies report that cardiovascular stability is maintained with pancuronium in the presence of cardiovascular depressing anaesthetic agents. ${ }^{1.2 .5 .13,15-17}$ This cardiovascular stability has been attributed to a vagolytic effect on the heart resulting in increased heart rate and cardiac output. ${ }^{16.17}$ This vagolytic effect may be due to a ganglionic ${ }^{3,13}$ or a post-ganglionic muscarinic blocking effect, ${ }^{13,18}$ but these have not been investigated in man. Further, there have been no reports on the interaction of this agent with homeostatic cardiovascular reflex mechanisms, in particular, the baroreflex.

The purpose of this study is to measure the effect of pancuronium on vagal slowing of the heart, reflexly induced by an acute elevation of systemic blood pressure. By using this Pressor Test (PT) as described by Smyth, Sleight \& Pickering, ${ }^{19}$ we were able to observe the vagolytic effect of pancuronium as well as its effects on the baroreflex.

\section{METHOD}

The quantitation of baroreceptor reflex function (BRF) in terms of cardiac slowing to a pressor stimulus has been described in detail elsewhere. ${ }^{19,20}$ Only a brief summary will be presented here. The test is based on the observation that a hypertensive stimulus to the baroreceptor areas reflexly induces cardiac slowing. Direct arterial blood pressure and electrocardiogram are recorded simultaneously. Graded doses of a smooth muscle vasoconstrictor (angiotensin) sufficient to produce a transient increase in systolic blood pressure in the range of 20 to 30 torr or a significant lengthening of the pulse interval on the electrocardiogram are injected intravenously. By plotting the $R-R$ interval change in response to the appropriate systolic pressure pulses, a plot is obtained (see Figure 1). By using the least square technique, a linear relationship is found from which a slope can be calculated. The slope is expressed in milliseconds of $\mathrm{R}-\mathrm{R}$ interval change per torr increase in systolic blood pressure and is an expression of baroreflex sensitivity.

'From the Department of Anaesthesia, Health Science Centre (General) Winnipeg and the University of Manitoba.

Supported in part by a Grant from the Medical Research Council of Canada. 


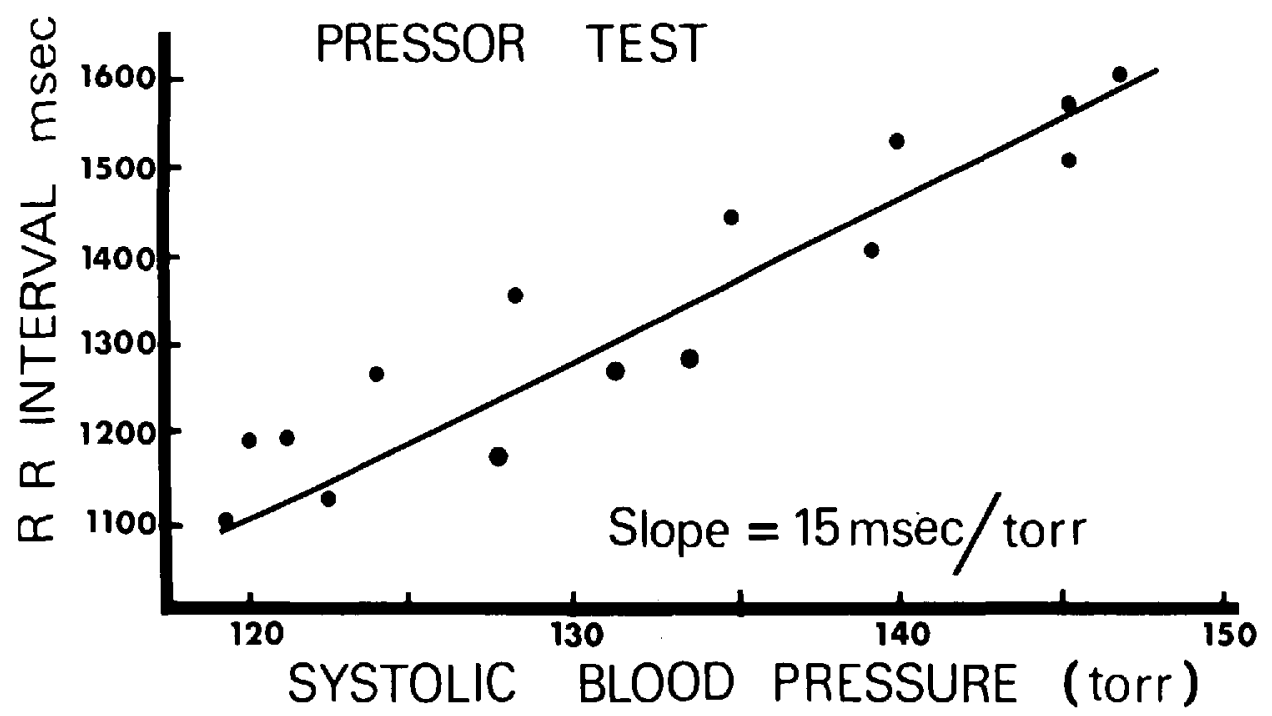

Figune 1. Systolic blood pressure (abscissa) plotted against the succeeding R-R interval (ordinate) for one subject. The relationship between the two parameters is represented by the computed line. The slope of this line expressed in milliseconds of $\mathrm{R}-\mathrm{R}$ interval change per Torr rise in systolic pressure is a quantitation of BRF.

Six healthy unpremedicated patients ranging in age from 21 to 24 years and undergoing minor surgical operations were studied. The subjects arrived in the operating room two hours before operation. An intravenous infusion was established in a large forearm vein. The radial artery was cannulated percutaneously under local anaesthesia. Direct arterial blood pressure was measured with a Statham 23 De strain gauge and recorded on a Hewlett-Packard polygraph simultaneously with lead 2 of a standard three-limb electrocardiogram. A pneumograph was placed about each subject's thorax to allow for exclusion of the effects of respiration on baroreceptor sensitivity. ${ }^{19.20}$ Thus R-R intervals and the corresponding systolic pressure during inspiration are excluded from calculations. Each subject's ventilation was then controlled with an Ohio anaesthetic ventilator (Model 300) in a semi-closed anaesthetic circuit. Air leaks were prevented by a nose clamp and a tightly fitting mouthpiece. A Pressor Test (PT) was performed once the subject was stabilized. The dose of angiotensin administered ranged between 2 and 7.5 micrograms. This period of study was designated as the "awake control" ( $\mathrm{AC})$.

Anaesthesia was then induced by mask with methoxyflurane in oxygen. Once the subjects were anaesthetized, 1 milligram/kilogram of succinylcholine was administered to facilitate tracheal intubation. Ventilation was then controlled at values similar to the awake control period. End-tidal methoxyflurane concentrations were monitored using a Beckman IR-215A infra-red analyzer. Once anaesthetic equilibration had occurred, the end-tidal methoxyflurane concentration was maintained between 0.20 and 0.22 per cent. This represents a minimal alveolar concentration or MAC of approximately $1.25 .^{21,22}$ To ensure adequate equilibration between blood, lungs and brain, adequate time was allowed until the inspired to end-tidal methoxyflurane difference was 0.02 per cent or less. We 


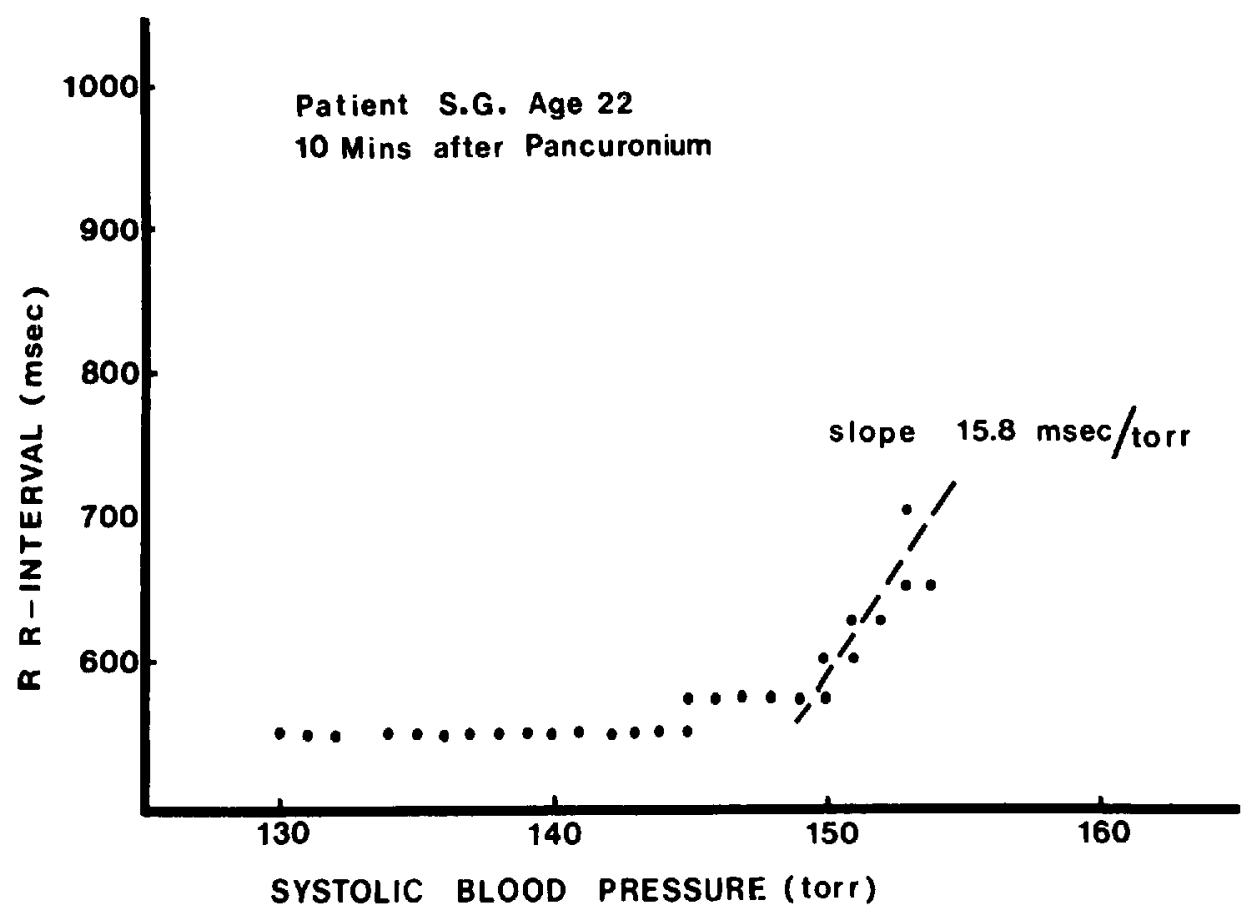

Figure 2. Typical "hockey stick" pressor test plot for one subject following the administration of pancuronium. Slope is computed from the "blade" of the "hockey stick" (see text for details).

had previously determined that this alveolar concentration of methoxyflurane does not alter baroreceptor reflex function. ${ }^{23}$ A Pressor Test was then performed on each subject. This period of study represents the methoxyflurane control study (MC).

Once the blood pressure and heart rate had returned to baseline values (usually within 5 minutes), pancuronium 0.11 milligrams/kilogram was administered intravenously. Pressor Tests were performed at 4-, 10-, and 15-minute periods after the injection of pancuronium. This period represents the pancuronium study (PS).

For comparison arterial blood samples were drawn during each study period for determination of $\mathrm{PaO}_{2}, \mathrm{PaCO}_{2}$ and $\mathrm{pH}$. All subjects were excluded for whom slopes of correlation coefficients were below 0.68 or where a probability value derived from the correlation coefficient was more than 0.05 . The mean, with or without the standard deviation of each Pressor Test performed during the three study periods, were compared to one another by utilizing the analysis of variance technique and the least significant difference test (LSD) to the 5 per cent level.

\section{RESULTS}

Figure 2 is a typical Pressor Test response in one subject following the administration of pancuronium. The plot configuration represents a "hockey stick." There is initially a pressure rise following the administration of angiotensin 


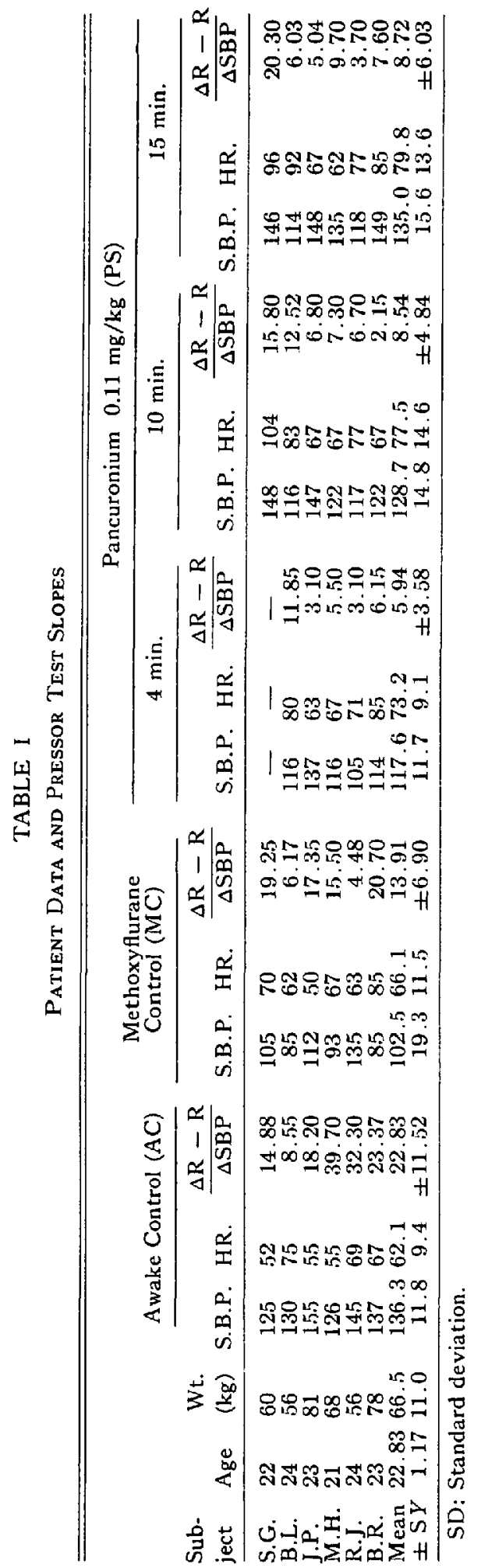




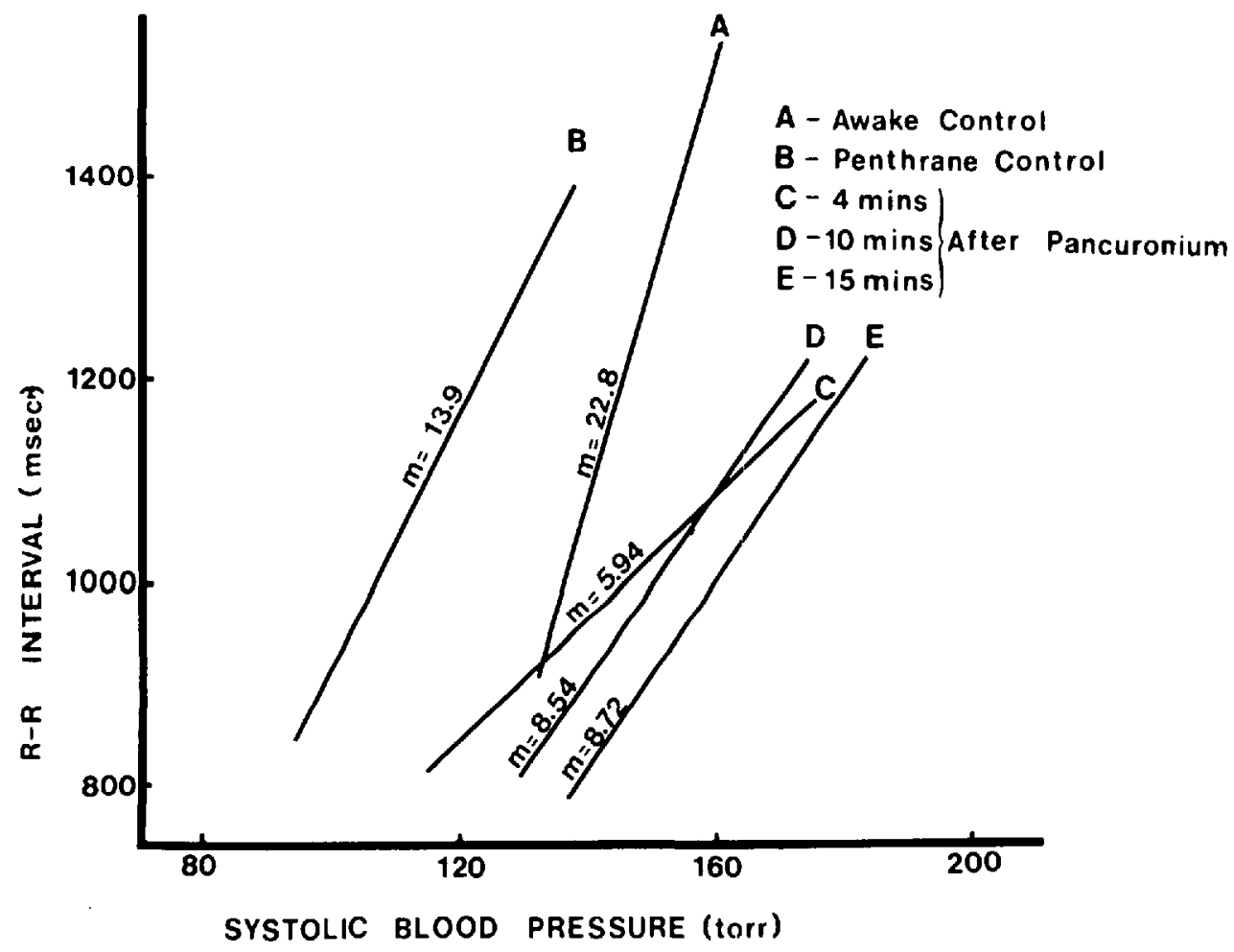

Ficure 3. Comparison of the means of all the study periods. The three mean slopes calculated after the administration of pancuronium are significantly different from the AC $(p<0.05)$ and only significanly different from the MC at the 0.10 level.

with little change in the R-R interval (the handle of the hockey stick). When a certain pressure elevation is reached, the $R-R$ interval lengthens with a systolic pressure increase (the blade of the hockey stick). This "hockey stick" effect was observed in all subjects who had Pressor Tests performed after the administration of pancuronium. The calculated slope of each subject is derived from the blade of the hockey stick. One subject's slope (SG) was excluded during the 4-minute pancuronium study on the basis of a poor correlation coefficient. Pertinent data and the slopes calculated during the three observation periods are shown in Table I. The mean slopes obtained during the various study periods are shown in Figure 3. The slopes obtained during the "awake" and "methoxyflurane" controls are significantly different from one another $(p<0.05)$. This is not in accordance with previous data from our laboratory ${ }^{23}$ where we reported no significant change in slope after methoxyflurane. The three mean slopes obtained during the pancuronium study are significantly different at the 0.05 level when compared to the awake controls, but are significantly different from the methoxyflurane controls only at the 0.10 level.

Arterial blood gases and $\mathrm{pH}$ studies varied little from control values throughout the study and are not reported. Systolic blood pressures and heart rates listed in Table I are baseline values obtained just prior to the administration of angiotensin. 


\section{Discussion}

We have previously reported that methoxyflurane at 1.5 and 2 MAC does not depress baroreflex activity when compared to awake controls using the same Pressor Test. The discrepancy between our awake and anaesthetized controls can be explained on the basis that too few subjects were studied. We felt that increasing the number of subjects in our studies was not warranted because of the frequent reports of nephrotoxicity of methoxyflurane. ${ }^{24}$ Consequently we pooled the awake and anaesthetized control slopes from our previous study ${ }^{23}$ with our present awake and methoxyflurane control slopes, and found no significant difference between the mean values of the two control groups $(\mathrm{AC}=22.9$ and $\mathrm{MC}=19.6$ ).

We have shown that as systolic blood pressure increases initially there is no change in heart rate until a particular pressure is reached. The latter phenomena can be explained on the basis that although the baroreceptors are being stimulated, the reflex heart rate response is initially antagonized by the muscarinic and possibly ganglionic blocking effect of pancuronium. With additional pressure rise and hence enhanced baroreceptor stimulation, the partial vagal blockade is overcome and the heart rate slows as depicted by the blade of the hockey stick. It is well known that the heart is under sympathetic as well as parasympathetic control. Baroreceptor responses to acute blood pressure elevation results in an augmentation of parasympathetic impulse with a paradoxical inhibition of sympathetic impulses to the heart. ${ }^{25.28} \mathrm{We}$ are unaware of any studies of the effect of pancuronium on sympathetic nervous function; therefore, we cannot comment on the action of the drug on this aspect of reflex autonomic cardiac rate regulation.

Because there is some preservation of the baroreflex in the presence of high doses of pancuronium, hypertensive or hypotensive responses occurring during similar anaesthesia should be partially counteracted. In subjects who have some defect in their baroreflex pathways, such as the hypertensive, ${ }^{20}$ the elderly, or subjects under halothane anaesthesia, ${ }^{27.28}$ this benefit of preservation of the reflex with pancuronium will not be apparent.

It should be noted that the dosage of pancuronium used in this study was large ( $0.11 \mathrm{milligram} /$ kilogram). Similar studies with comparable doses of d-tubocurarine in the same model were difficult to interpret. There was a marked variation in blood pressure, especially during controlled ventilation. This made it extremely difficult to relate heart rate and pressure changes to one another following the administration of the vasopressor.

\section{SumMary}

We have shown that the baroreflex is partially maintained in patients anaesthetized with methoxyflurane following the administration of pancuronium. Initially heart rate responses are counteracted by the vagolytic effect of pancuronium, which might be explained by a muscarinic and/or ganglionic blocking property of the drug. 


\section{RÉSUMÉ}

Nous avons montré que la réponse à la stimulation des barorecepteurs est partiellement maintenue chez les patients anesthésiés au Méthoxyflurane suivant l'administration de Pancuronium. Initialement la réponse cardiaque est contrecarrée par l'effet vagolytique du Pancuronium, ce qui peut s'expliquer par la propriété muscarinique et/ou la propriété ganglioplégique du médicament.

\section{REFERENCES}

1. McDoweli, S.A. \& Clarke, R.S.J, A clinical comparison of pancuronium with d-tubocurarine. Anesthesia 24:581.

2. Katz, R.L. Clinical neuromuscular pharmacology of pancuronium. Anesthesia 34: 550 .

3. Buckett, W.R., Marjoribanks, C.E.B., Marwick, F.A., \& Monton, M.B. The Pharmacology of Pancuronium Bromide (Org. NA97), A new potent steroidal neuromuscular blocking agent. British Journal of Pharmacology \& Chemotherapy 32: 671.

4. Stover, J. \& Lund, I. Dose response curves for tubocurarine, alcuronium and pancuronium. Acta Anesth. Scand. Suppl. 37: 328 (1970).

5. Smith. G., Proctor, D.W., \& Spence, A.A. A comparison of some cardiovascular effects of tubocurarine and pancuronium in dogs. Brit. J. Anaes. 42: 923 (1970).

6. SMith, N.T. \& Whitchen, C.F. Hemodynamic effects of gallamine and tubocurarine administration during halothane anesthesia. J.A.M.A. 100: 114 (1967).

7. Meill, R.S. \& Nixon, B.A. Halothane and tubocurarine. Anesthesia 20: 250 (1965).

8. Longnecker, D.E., Stoelting, R.K., \& Morrow, A.G. Cardiac and peripheral vascular effects of d-tubocurarine in man. Anesthesia \& Analgesia 42: 660 (1970).

9. Stoelting, R.K. Blood pressure responses to d-tubocurarine and its preservatives in anesthetized patients. Anesthesiology 35: 315 (1971).

10. McCullough, L.S., Reier, C.E., \& Delanois, A.L. The effects of d-tubocurarine on spontaneous postganglionic sympathetic activity and histamine release. Anesthesiology 33: 328 (1970).

11. Eccles, R.M. \& Libet, B. Origin and blockade of the synaptic responses of curarized sympathetic ganglia. J. Physiology 157: 489 (1961).

12. BAnd, W.L.M. Some clinical experience with pancuronium bromide. Irish J. Med. Sci. 1: 559 (1968).

13. Bonta, I., Goorissen, E.M., \& Derk, F.H. Pharmacological interaction between pancuronium bromide and anesthesia. Europ. J. Pharmacol. 4: 8.3 (1968).

14. BAIRD, W.L.M. \& REID, A.M. The neuromuscular blocking properties of a new steroid compound pancuronium bromide. Brit. J. Anesth. 39: 775 (1967).

15. BonTA, L. \& Goonissen, E.M. Different potency of pancuronium bromide on two types of skeletal muscle. European J. Pharmacol. 4: 303 ( 1968).

16. Komesaroff, D. \& Field, J.E. Pancuronium bromide: a new non-depolarizing muscle relaxant. Med. J. Aust. 9: 908 (1969).

17. Kelman, G.R. \& Kennedy, B.R. Cardiovascular affects of pancuronium in man. Brit. J. Anesth. 43: 335 (1971).

18. Bonta, I.L. \& Saxena, P.R. Mechanism of selective cardiac vagolytic action of pancuronium bromide. Specific blockade of cardiac muscarinic receptors. European J. Pharmacol. 11: 332 (1970).

19. Smyth, H.S., Sleight, P., \& Pickerinc, G.W. Reflex regulation of arterial pressure during sleep in man. A quantitative method of assessing baroreflex sensitivity. Circulation Research Vol. XXIV, January (1969).

20. Buistow, J.D., Honour, A.J., Pickering, G.W., Sleight, P., \& Smyth, H.S. Diminished baroreflex sensitivity in high blood pressure. Circulation Vol. XXXIX, January (1969).

21. Ecer, E.I., Samman, L.J., \& Brandstater, B. Minimum alveolar anesthetic concentration: a standard of anesthetic potency. Anesthesiology 26: 756 (1965).

22. Saidman, L.J., Eger, E.I., Munson, E.S,, Babao, A.A., \& Muallem, M. Minimum alveolar concentrations of methoxyflurane, halothane, ether and cyclopropane in man: correlations with theories of anesthesia. Anesthesiology 28: 994 (1967). 
23. MittLER, G. \& WAdE, J. The effect of methoxyflurane on baroreflex control of heart rate in man. Canad. Anaesth. Soc. J. 19: 60 (1972).

24. Committee on anesthesia, National academy of Sciences, National Research Council. Statement regarding the role of methoxyflurane in the production of renal dysfunction. Anesthesiology 34: 505 (1971).

25. DeVleeschnouwer, G.R. \& Heymans, C. Baroreceptors and reflex regulation of heart rate. Baroreceptors and hypertension. New York. Pergamon Press (1967). Edited by P. KEDZI. pp. 187-190.

26. Thames, M.D. \& Kontas, H.A. Mechanisms of baroreceptor-induced changes in heart rate. Am. J. Physiol. 218: 106 (1964).

27. Bristow, J., Prys-Roberts, C., Fisher, A., \& Pickering, M.B. Effects of anesthesia on baroreflex control of heart rate in man. Anesthesiology 31:422 (1969).

28. Duke, P.C., Wade, J.G., Hickey, R., \& Larson, C.P. The effects of age on baroreceptor function in man. Abstract of Scientific Papers. American Society of Anesthesiology Annual Meeting 1969. 